\title{
An Effective Interval-Valued Intuitionistic Fuzzy Entropy to Evaluate Entrepreneurship Orientation of Online P2P Lending Platforms
}

\author{
Xiaohong Chen, Li Yang, Pei Wang, and Wei Yue \\ Business School, Central South University, Changsha 410083, China \\ Correspondence should be addressed to Li Yang; yangli@csu.edu.cn
}

Received 25 January 2013; Accepted 2 August 2013

Academic Editor: Christian Maes

Copyright (c) 2013 Xiaohong Chen et al. This is an open access article distributed under the Creative Commons Attribution License, which permits unrestricted use, distribution, and reproduction in any medium, provided the original work is properly cited.

This paper describes an approach to measure the entrepreneurship orientation of online P2P lending platforms. The limitations of existing methods for calculating entropy of interval-valued intuitionistic fuzzy sets (IVIFSs) are significantly improved by a new entropy measure of IVIFS considered in this paper, and then the essential properties of the proposed entropy are introduced. Moreover, an evaluation procedure is proposed to measure entrepreneurship orientation of online P2P lending platforms. Finally, a case is used to demonstrate the effectiveness of this method.

\section{Introduction}

With the enormous popularity of online communities, a new way of loan origination has entered the credit market: online peer-to-peer (P2P) lending [1]. Online P2P lending platforms are financial institutions operating without the participation of traditional financial intermediaries. Although online P2P lending is a relatively young field of research, an increasing amount of scientific contributions has been published in recent years. The main research is focused on stakeholders (Herzenstein et al., 2008 [2]; Klafft, 2008 [3]; Galloway, 2009 [4]), funding success factors (Kumar, 2007 [5]; Lin, 2009 [6]; Larrimore et al., 2009 [7]; Duarte et al., 2012 [8]; Burtch et al., 2013 [9]), determinants of interest rates factors (Pope and Sydnor, 2011 [10]; Iyer et al., 2009 [11]; Collier and Hampshire, 2010 [12]; Brandes et al., 2011 [13]), and lenders' behavior (Shen et al., 2010 [14]; Yum et al., 2012 [15]; Dezs and Loewenstein, 2012 [16]; Zhang and Liu [17]). The online P2P lending platforms are firms, and they need to acquire entrepreneurial competences to survive. The processes of strategy-making and the styles of firms engaging in entrepreneurial activities are together referred to as "entrepreneurship orientation" (EO) [18]. Several studies have found a positive relationship between EO and firm performance (e.g., $[19,20])$. Consequently, measuring EO of online P2P lending platforms is of special importance for firms and for organizations, such as venture capitalists, business angels, and governments.

Variations in the weights often influence the rankings of the alternatives [21]. The weights can be classified into subjective weights and objective weights depending on the information source. The most well-known method of generating objective weights is the entropy method [22]. Entropy has been the main tool for measuring uncertain information since information theory was conceived in the work of Shannon [23] more than sixty years ago. Fuzziness, a feature of imperfect information, results from the lack of crisp distinction between the elements belonging and not belonging to a set; that is, the boundaries of the set under consideration are not sharply defined [24]. Entropy has also been concerned as a measure of fuzziness since fuzzy entropy was first mentioned in 1965 by Zadeh [25]. de Luca and Termini [26] proposed a fuzzy entropy based on Shannon's function. Kaufmann [27] proposed to measure the degree of fuzziness of any fuzzy set by a metric distance between its membership function and the membership function (characteristic function) of its nearest crisp set. Another way given by Yager [28] was to view the degree of fuzziness in terms of a lack of distinction between the fuzzy 
set and its complement. Higashi and Klir [29] showed the entropy measure as the difference between two fuzzy sets. Kosko [30-32] investigated the fuzzy entropy in relation to a measure of subsethood. Parkash et al. [33] have developed two new measures of weighed fuzzy entropy, the findings of which have been applied to study the principle of maximum weighed fuzzy entropy. Lotfi and Fallahnejad [34] extended Shannon's entropy method for fuzzy data based on $\alpha$-level sets.

The theory of fuzzy sets (FSs) proposed by Zadeh [25] has achieved a great success in various fields. Later, a lot of generalized forms of FSs have been proposed. The classical sets include interval-valued fuzzy sets (IVFSs) [35], intuitionistic fuzzy sets (IFSs) [36], interval-valued intuitionistic fuzzy sets (IVIFSs) [37], and vague sets [38]. Burillo and Bustince [39] introduced the notion that entropy of IVFSs and IFSs can be used to evaluate the degree of intuitionism of an IVFS or IFS. Szimidt and Kacprzyk [24] proposed a nonprobabilistictype entropy measure with a geometric interpretation of IFSs. Hung and Yang [40] gave their axiomatic definitions of entropy of IFSs and IVFSs by exploiting the concept of probability. Zhang and Jiang [41] proposed nonprobabilistic entropy of a vague set by means of the intersection and union of the membership degree and nonmembership degree of the vague set. Ye [42] proposed two effective entropy measures for IVFSs. Wei et al. [43] gave an entropy measure for IVIFSs based on three entropy measures defined independently by Szmidt and Kacprzyk [24], Wang and Lei [44], and Huang and Liu [45]. Zhang et al. [46] proposed a new information entropy measure of interval-valued intuitionistic fuzzy set by using membership interval and nonmembership interval of IVIFSs, which complied with the extended form of de Luca and Termini [26] axioms for fuzzy entropy.

From [47-49], it turns out that IVFS theory is equivalent to IFS theory, which is equivalent to vague set theory, and IVIFS theory extends IFS theory. At the same time, some existing entropy measures for IVIFSs are not always effective in some cases. The focus of this study is on apparent weaknesses of these entropy measures. In this paper, we propose a novel formula to calculate the entropy of an IVIFS on the basis of the argument on the relationship among the entropies given in $[50,51]$ and use it to evaluate entrepreneurship orientation of online $\mathrm{P} 2 \mathrm{P}$ lending platforms. The rest of this paper is organized as follows. In Section 2, we introduce some basic notions of IFS and IVIFSs. In Section 3, we propose a new entropy measure of interval-valued intuitionistic fuzzy set by using cotangent function. Two numeral examples are given to demonstrate the effectiveness by the comparison of the proposed entropy and existing entropy [50, 51]. In Section 4, we use the new entropy to evaluate entrepreneurship orientation of online $\mathrm{P} 2 \mathrm{P}$ lending platforms. Concluding remarks are made in Section 5.

\section{Preliminaries}

Here, we give a brief review of some preliminaries.

Definition 1 (see [37]). Let $D[0,1]$ be the set of all closed subintervals of the interval $[0,1]$ and $X$ an ordinary finite nonempty set. An interval-valued intuitionistic fuzzy set (IVIFS) in $X$ is an expression given by

$$
A=\left\{\left\langle x, \tilde{\mu}_{A}(x), \widetilde{v}_{A}(x)\right\rangle \mid x \in X\right\},
$$

$x$ in the set $A$, respectively, where

$$
\begin{gathered}
\tilde{\mu}_{A}: X \rightarrow D[0,1], \\
\tilde{\nu}_{A}: X \rightarrow D[0,1]
\end{gathered}
$$

with the condition $0 \leq \sup \left(\tilde{\mu}_{A}(x)\right)+\sup \left(\nu_{A}(x)\right) \leq 1$ for any $x \in X$.

The intervals $\tilde{\mu}_{A}(x)$ and $\widetilde{v}_{A}(x)$ denote the degree of membership and nonmembership of the element $x$ in the set $A$, respectively.

For convenience, let $\tilde{\mu}_{A}(x)=\left[\mu_{A L}(x), \mu_{A U}(x)\right], \widetilde{v}_{A}(x)=$ $\left[v_{A L}(x), v_{A U}(x)\right] ;$ then

$$
A=\left\{\left\langle x,\left[\mu_{A L}(x), \mu_{A U}(x)\right],\left[v_{A L}(x), v_{A U}(x)\right]\right\rangle \mid x \in X\right\},
$$

where $0 \leq \mu_{A U}(x)+v_{A U}(x) \leq 1, \mu_{A L}(x) \geq 0, v_{A L}(x) \geq 0$.

For each element $x$, we can compute the hesitancy degree of an intuitionistic fuzzy interval of $x \in X$ in $A$ defined as follows:

$$
\begin{aligned}
\tilde{\pi}_{A}(x) & =1-\tilde{\mu}_{A}(x)-\widetilde{v}_{A}(x) \\
& =\left[1-\mu_{A U}(x)-v_{A U}(x), 1-\mu_{A L}(x)-v_{A L}(x)\right] .
\end{aligned}
$$

For convenience, an IVIFS value is denoted by $A=$ $([a, b],[c, d])$.

Definition 2 (see [37]). Let $A, B \in \operatorname{IVIFS}(X)$; then some operations can be defined as follows:

$$
\begin{array}{r}
A \cup B=\left\{\left\langlex_{i},\left[\mu_{A L}\left(x_{i}\right) \vee \mu_{B L}\left(x_{i}\right), \mu_{A U}\left(x_{i}\right) \vee \mu_{B U}\left(x_{i}\right)\right],\right.\right. \\
\left.\left.\left[v_{A L}\left(x_{i}\right) \wedge v_{B L}\left(x_{i}\right), v_{A U}\left(x_{i}\right) \wedge v_{B U}\left(x_{i}\right)\right]\right\rangle\right\}, \\
A \cap B=\left\{\left\langlex_{i},\left[\mu_{A L}\left(x_{i}\right) \wedge \mu_{B L}\left(x_{i}\right), \mu_{A U}\left(x_{i}\right) \wedge \mu_{B U}\left(x_{i}\right)\right],\right.\right. \\
\left.\left.\left[v_{A L}\left(x_{i}\right) \vee v_{B L}\left(x_{i}\right), v_{A U}\left(x_{i}\right) \vee v_{B U}\left(x_{i}\right)\right]\right\rangle\right\} .
\end{array}
$$

The following expressions are defined in [37] for all $A, B \in$ $\operatorname{IVFSs}(X)$ :

$A \subseteq B$ if and only if $\mu_{A L} \leq \mu_{B L}, \mu_{A U} \leq \mu_{B U}, \nu_{A L} \geq \nu_{B L}$ and $v_{A U} \geq v_{B U}$ for all $x \in X$,

$A=B$ if and only if $A \subseteq B$ and $B \subseteq A$ for all $x \in X$,

$A^{C}=\left\{\left\langle x,\left[v_{A L}(x), v_{A U}(x)\right],\left[\mu_{A L}(x), \mu_{A U}(x)\right]\right\rangle \mid x \in\right.$ $X\}$.

In the following, we introduce two weighed aggregation operators related to IVIFSs [52]. 
Definition 3 (see [52]). Let $A_{j}(j=1,2, \ldots, n) \in \operatorname{IVIFS}(X)$. The weighed geometric average operator (IVIF-WGA operator) is defined by

$$
\begin{aligned}
& F_{w}\left(A_{1}, A_{2}, \ldots, A_{n}\right) \\
&=\left(\left[\prod_{j=1}^{n} \mu_{A_{j} L}(x)^{w_{j}}, \prod_{j=1}^{n} \mu_{A_{j} U}(x)^{w_{j}}\right],\right. \\
& {\left.\left[1-\prod_{j=1}^{n}\left(1-v_{A_{j} L}(x)\right)^{w_{j}}, 1-\prod_{j=1}^{n}\left(1-v_{A_{j} U}(x)\right)^{w_{j}}\right]\right), }
\end{aligned}
$$

where $w_{j}$ is the weight of $A_{j}(j=1,2, \ldots, n), w_{j} \in[0,1]$ and $\sum_{j=1}^{n} w_{j}=1$. In particular, assuming that $w_{j}=1 / n(j=$ $1,2, \ldots, n)$, then $F_{w}$ is called an arithmetic average operator for IVIFSs.

Definition 4 (see [53]). Let $A=([a, b],[c, d])$ be an intervalvalued intuitionistic fuzzy number; a score function $S$ of an interval-valued intuitionistic fuzzy value can be represented as follows:

$$
S(A)=\frac{a-c+b-d}{2} .
$$

Definition 5 (see [53]). Let $A_{1}=\left(\left[a_{1}, b_{1}\right],\left[c_{1}, d_{1}\right]\right)$ and $A_{2}=$ $\left(\left[a_{2}, b_{2}\right],\left[c_{2}, d_{2}\right]\right)$ be two interval-valued intuitionistic fuzzy values and $S\left(A_{1}\right)=\left(a_{1}-c_{1}+b_{1}-d_{1}\right) / 2$ and $S\left(A_{2}\right)=$ $\left(a_{2}-c_{2}+b_{2}-d_{2}\right) / 2$ the scores of $A_{1}$ and $A_{2}$, respectively; then if $S\left(A_{1}\right)<S\left(A_{2}\right)$, then $A_{1}$ is smaller than $A_{2}$, denoted by $A_{1}<A_{2}$.

Definition 6 (see [43]). A real-valued function $E$ : $\operatorname{IVIFS}(X) \rightarrow[0,1]$ is called an entropy measure on $\operatorname{IVIFS}(X)$ if it satisfies the following axiomatic requirements:

(P1) $E(A)=0$, if and only if $A$ is a crisp set,

(P2) $E(A)=1$, if and only if $\tilde{\mu}_{A}\left(x_{i}\right)=\widetilde{v}_{A}\left(x_{i}\right)$ for all $x_{i} \in X$,

(P3) $E(A)=E\left(A^{C}\right)$ for all $x_{i} \in \operatorname{IVIFS}(X)$,

(P4) $E(A) \leq E(B)$ if $A$ is less fuzzy than $B$, that is, $\mu_{A L}\left(x_{i}\right) \leq$ $v_{A L}\left(x_{i}\right), \mu_{A U}\left(x_{i}\right) \leq v_{A U}\left(x_{i}\right)$ and $A \subseteq B$ for all $x_{i} \in X$ or $\mu_{A L}\left(x_{i}\right) \geq v_{A L}\left(x_{i}\right), \mu_{A U}\left(x_{i}\right) \geq v_{A U}\left(x_{i}\right)$ and $B \subseteq A$ for all $x_{i} \in X$.

\section{An Effective Interval-Valued Intuitionistic Fuzzy Entropy}

3.1. The Limitations of the Existing Interval-Valued Intuitionistic Fuzzy Entropy. Let us suppose that $E\left(A_{i}\right)$ is the entropy of IVIFSs for convenience.

Vlachos' entropy measure [50]:

$$
\begin{aligned}
& E^{1}(A) \\
& =1-\sqrt{\frac{1}{2 n} \sum_{i=1}^{n}\left(\left|\mu_{A L}\left(x_{i}\right)-v_{A L}\left(x_{i}\right)\right|\right)^{2}+\left(\left|\mu_{A U}\left(x_{i}\right)-v_{A U}\left(x_{i}\right)\right|\right)^{2}} .
\end{aligned}
$$

Example 7. Let $A=([0.4,0.5],[0.3,0.4])$ and $B=([0.2,0.3]$, $[0.1,0.2])$ be two IVIFSs in $X$.

Intuitively, we can see that $B$ is more fuzzy than $A$. Now, we calculate the $E^{1}(A)$ and $E^{1}(B)$ by $(8)$, and we can obtain

$$
\begin{aligned}
& E^{1}(A)=1-\sqrt{\frac{1}{2}\left(|0.4-0.3|^{2}+|0.5-0.4|^{2}\right)}=0.9, \\
& E^{1}(B)=1-\sqrt{\frac{1}{2}\left(|0.2-0.1|^{2}+|0.3-0.2|^{2}\right)}=0.9,
\end{aligned}
$$

which indicate that $E^{1}(A)=E^{1}(B)$ is not consistent with our intuition.

Ye's entropy measures [51]:

$$
\begin{aligned}
& E^{2}(A)= \\
& \left\{\sin \frac{\pi \times\left[1+\mu_{A L}\left(x_{i}\right)+p W_{\mu A}\left(x_{i}\right)-v_{A L}\left(x_{i}\right)-q W_{\nu A}\left(x_{i}\right)\right]}{4}\right. \\
& \quad+\sin \frac{\pi \times\left[1-\mu_{A L}\left(x_{i}\right)-p W_{\mu A}\left(x_{i}\right)+\nu_{A L}\left(x_{i}\right)+q W_{\nu A}\left(x_{i}\right)\right]}{4} \\
& \quad-1\} \times \frac{1}{\sqrt{2}-1},
\end{aligned}
$$

where $p, q \in[0,1]$ representes two fixed numbers, $W_{\mu A}(x)=$ $\mu_{A U}(x)-\mu_{A L}(x)$ and $W_{\nu A}(x)=v_{A U}(x)-v_{A L}(x)$.

Example 8. Let $A=([0.6,0.6],[0.2,0.2])$ and $B=([0.7,0.7]$, $[0.3,0.3])$ be two IVIFSs in $X$.

Intuitively, $A$ is more fuzzy than $B$. Now the $E^{2}(A)$ and $E^{2}(B)$ can be gained by (10), and taking $p=q=0.5$, the results are

$$
\begin{aligned}
& E^{2}(A) \\
& =\left\{\sin \frac{\pi \times[1+0.6-0.2]}{4}+\sin \frac{\pi \times[1-0.6+0.2]}{4}-1\right\} \\
& \quad \times \frac{1}{\sqrt{2}-1}=0.833, \\
& E^{2}(B) \\
& =\left\{\sin \frac{\pi \times[1+0.7-0.3]}{4}+\sin \frac{\pi \times[1-0.7+0.3]}{4}-1\right\} \\
& \quad \times \frac{1}{\sqrt{2}-1}=0.833,
\end{aligned}
$$

which indicates that $E^{2}(A)=E^{2}(B)$ is not consistent with our intuition.

3.2. New Interval-Valued Intuitionistic Fuzzy Entropy. A new interval-valued intuitionistic fuzzy entropy measure is introduced in what follows.

Definition 9. Assuming that $A \in \operatorname{IVIFS}(X)$, then an intervalvalued intuitionistic fuzzy entropy measure can be defined as 


$$
E(A)=1-\sqrt{\frac{1}{2 n} \sum_{i=1}^{n}\left(\left(\mu_{A L}\left(x_{i}\right)-v_{A L}\left(x_{i}\right)\right) \times\left(1-\pi_{A L}\left(x_{i}\right)\right)\right)^{2}+\left(\left(\mu_{A U}\left(x_{i}\right)-\nu_{A U}\left(x_{i}\right)\right) \times\left(1-\pi_{A U}\left(x_{i}\right)\right)\right)^{2}} .
$$

Theorem 10. The mapping $E(A)$, defined by (12), is an entropy measure for IVIFSs.

Proof. In order for (12) to be qualified as a sensible measure of interval-valued intuitionistic fuzzy entropy, it must satisfy the conditions (P1)-(P4) in Definition 6.

(P1) Let $A$ be a crisp set. Then, we have $\tilde{\pi}_{A}\left(x_{i}\right)=0$, $\tilde{\mu}_{A}\left(x_{i}\right)=1$ and $\widetilde{v}_{A}\left(x_{i}\right)=0$, or $\tilde{\pi}_{A}\left(x_{i}\right)=0, \tilde{\mu}_{A}\left(x_{i}\right)=0$ and $\widetilde{v}_{A}\left(x_{i}\right)=1$. So, $E(A)=0$.

(P2) Let $\tilde{\mu}_{A}\left(x_{i}\right)=\widetilde{\nu}_{B}\left(x_{i}\right)$; we can obtain $E(A)=1$.

(P3) It is clear that $A^{C}=\left\{\left\langle x_{i},\left[v_{A L}\left(x_{i}\right), v_{A U}\left(x_{i}\right)\right],\left[\mu_{A L}\left(x_{i}\right)\right.\right.\right.$, $\left.\left.\left.\mu_{A U}\left(x_{i}\right)\right]\right\rangle \mid x_{i} \in X\right\}$. By applying (12), we have $E(A)=$ $E\left(A^{C}\right)$.

(P4) In order to show that (12) fulfills the requirement of (P4), they suffice to prove the following function:

$$
\begin{aligned}
& \left(\left(\mu_{A L}\left(x_{i}\right)\right)^{2}-\left(\nu_{A L}\left(x_{i}\right)\right)^{2}\right)^{2}+\left(\left(\mu_{A U}\left(x_{i}\right)\right)^{2}-\left(\nu_{A U}\left(x_{i}\right)\right)^{2}\right)^{2} \\
& \geq\left(\left(\mu_{B L}\left(x_{i}\right)\right)^{2}-\left(\nu_{B L}\left(x_{i}\right)\right)^{2}\right)^{2}+\left(\left(\mu_{B U}\left(x_{i}\right)\right)^{2}-\left(\nu_{B U}\left(x_{i}\right)\right)^{2}\right)^{2},
\end{aligned}
$$

where function $E$ is monotonically decreasing.
Suppose that $\mu_{B L}\left(x_{i}\right) \leq \nu_{B L}\left(x_{i}\right), \mu_{B U}\left(x_{i}\right) \leq v_{B U}\left(x_{i}\right)$ and $A \subseteq B$; in order to prove (13), namely, we prove (14):

$$
\begin{gathered}
\left(v_{A L}\left(x_{i}\right)\right)^{2}-\left(\mu_{A L}\left(x_{i}\right)\right)^{2} \geq\left(v_{B L}\left(x_{i}\right)\right)^{2}-\left(\mu_{B L}\left(x_{i}\right)\right)^{2}, \\
\left(v_{A U}\left(x_{i}\right)\right)^{2}-\left(\mu_{A U}\left(x_{i}\right)\right)^{2} \geq\left(v_{B U}\left(x_{i}\right)\right)^{2}-\left(\mu_{B U}\left(x_{i}\right)\right)^{2} .
\end{gathered}
$$

If $v_{A L}\left(x_{i}\right) \geq v_{B L}\left(x_{i}\right)$ and $\mu_{A L}\left(x_{i}\right) \leq \mu_{B L}\left(x_{i}\right)$, then it follows that $\left(v_{A L}\left(x_{i}\right)\right)^{2}-\left(\mu_{A L}\left(x_{i}\right)\right)^{2} \geq\left(v_{B L}\left(x_{i}\right)\right)^{2}-\left(\mu_{B L}\left(x_{i}\right)\right)^{2}$. If $v_{A U}\left(x_{i}\right) \geq$ $v_{B U}\left(x_{i}\right)$ and $\mu_{A U}\left(x_{i}\right) \leq \mu_{B U}\left(x_{i}\right)$, then we have $\left(v_{A U}\left(x_{i}\right)\right)^{2}-$ $\left(\mu_{A U}\left(x_{i}\right)\right)^{2} \geq\left(\nu_{B U}\left(x_{i}\right)\right)^{2}-\left(\mu_{B U}\left(x_{i}\right)\right)^{2}$. So, we can get that (14) holds. Therefore, $E(A) \leq E(B)$.

Similarly, when $\mu_{B L}\left(x_{i}\right) \geq v_{B L}\left(x_{i}\right), \mu_{B U}\left(x_{i}\right) \geq v_{B U}\left(x_{i}\right)$ and $B \subseteq A$, we can also prove that $E(A) \leq E(B)$.

\subsection{Numeric Examples for the New Interval-Valued Intuitionistic Fuzzy Entropy}

Example 11. Let $A=([0.4,0.5],[0.3,0.4])$ and $B=([0.2,0.3]$, $[0.1,0.2])$ be two IVIFSs in $X$.

Intuitively, we can see that $B$ is more fuzzy than $A$. Now we calculate the $E(A)$ and $E(B)$ by (12); we can obtain

$$
\begin{aligned}
& E(A)=1-\sqrt{\frac{1}{2}\left((|0.4-0.3| \times(1-(1-0.4-0.3)))^{2}+(|0.5-0.4| \times(1-(1-0.5-0.4)))^{2}\right)}=0.919 \\
& E(B)=1-\sqrt{\frac{1}{2}\left((|0.2-0.1| \times(1-(1-0.2-0.1)))^{2}+(|0.3-0.2| \times(1-(1-0.3-0.2)))^{2}\right)}=0.959
\end{aligned}
$$

which indicate that $E(A)<E(B)$ is consistent with our intuition. This result is better than the result in Example 7.
Intuitively, we can see that $A$ is more fuzzy than $B$. Now we calculate the $E(A)$ and $E(B)$ by (12); we can obtain

Example 12. Let $A=([0.6,0.6],[0.2,0.2])$ and $B=([0.7,0.7]$, $[0.3,0.3])$ be two IVIFSs in $X$.

$$
\begin{aligned}
& E(A)=1-\sqrt{\frac{1}{2}\left((|0.6-0.2| \times(1-(1-0.6-0.2)))^{2}+(|0.6-0.2| \times(1-(1-0.6-0.2)))^{2}\right)}=0.680 \\
& E(B)=1-\sqrt{\frac{1}{2}\left((|0.7-0.3| \times(1-(1-0.7-0.3)))^{2}+(|0.3-0.2| \times(1-(1-0.7-0.3)))^{2}\right)}=0.600
\end{aligned}
$$


which indicate that $E(A)>E(B)$ is consistent with our intuition. This result is better than the result in Example 8.

\section{Evaluating Entrepreneurship Orientation of Online P2P Lending Platforms}

In this section, we apply the proposed entropy to evaluate entrepreneurship orientation of online P2P lending platforms.

4.1. The Evaluation Procedure. Evaluate entrepreneurship orientation of online P2P lending platforms. Assume that there are $n$ alternatives $X=\left\{x_{1}, x_{2}, \ldots, x_{n}\right\}$ and $m$ evaluation criteria $C=\left\{c_{1}, c_{2}, \ldots, c_{m}\right\}$ with weight vector $W=$ $\left(w_{1}, w_{2}, \ldots, w_{m}\right)^{T}$ associated with $C$, where $w_{j} \in[0,1]$ and $\sum_{j=1}^{m} w_{j}=1$. Three evaluated criteria are considered, including innovativeness $\left(c_{1}\right)$, risk-taking $\left(c_{2}\right)$, and proactiveness $\left(c_{3}\right)[54,55]$. In this case, the characteristic of the alternative $A_{i}$ is represented by the following IVIFS:

$$
A_{i}=\left\{\left\langleC_{j},\left[\mu_{A_{i} L}\left(C_{j}\right), \mu_{A_{i} U}\left(C_{j}\right)\right],\right.\right.
$$

$$
\left.\left.\left[v_{A_{i} L}\left(C_{j}\right), v_{A_{i} U}\left(C_{j}\right)\right]\right\rangle \mid C_{j} \in C\right\},
$$

where $0 \leq \mu_{A_{i} U}\left(C_{j}\right)+v_{A_{i} U}\left(C_{j}\right) \leq 1, \mu_{A_{i} L}\left(C_{j}\right) \geq 0, \mu_{A_{i} L}\left(C_{j}\right) \geq$ $0, i=1,2, \ldots, n$, and $j=1,2, \ldots, m$. The IVIFS value, that is, the pair of intervals $\mu_{A_{i}}\left(C_{j}\right)=\left[a_{i j}, b_{i j}\right], v_{A_{i}}\left(C_{j}\right)=\left[c_{i j}, d_{i j}\right]$ for $C_{j} \in C$, is denoted by $r_{i j}=\left(\left[a_{i j}, b_{i j}\right],\left[c_{i j}, d_{i j}\right]\right)$ for convenience. Here, we can elicit an interval-valued intuitionistic fuzzy evaluation matrix $D=\left(r_{i j}\right)_{n \times m}$.

If the information about weight $w_{j}$ of the criterion $C_{j}(j=1,2, \ldots, m)$ is incomplete, for determining the criterion weight from the evaluation matrix $D=\left(r_{i j}\right)_{n \times m}$, we can establish a model of interval-valued intuitionistic fuzzy entropy weights.

For the criteria $C_{j}$, the entropy of the alternative $A_{i}$ can be given as

$$
E\left(r_{i j}\right)=1-\sqrt{\frac{1}{2}\left(\left(\mu_{A L}\left(r_{i j}\right)-v_{A L}\left(r_{i j}\right)\right) \times\left(1-\pi_{A L}\left(r_{i j}\right)\right)\right)^{2}+\left(\left(\mu_{A U}\left(r_{i j}\right)-v_{A U}\left(r_{i j}\right)\right) \times\left(1-\pi_{A U}\left(r_{i j}\right)\right)\right)^{2}}
$$

And the overall entropy for the alternative $A_{i}$ is given as

$$
E\left(A_{i}\right)=\sum_{j=1}^{m}\left(1-\sqrt{\frac{1}{2}\left(\left(\mu_{A L}\left(r_{i j}\right)-v_{A L}\left(r_{i j}\right)\right) \times\left(1-\pi_{A L}\left(r_{i j}\right)\right)\right)^{2}+\left(\left(\mu_{A U}\left(r_{i j}\right)-v_{A U}\left(r_{i j}\right)\right) \times\left(1-\pi_{A U}\left(r_{i j}\right)\right)\right)^{2}}\right) .
$$

According to the entropy theory, if the entropy value for an alternative is smaller across alternatives, it can provide decision makers with the useful information. Therefore, the criteria should be assigned a bigger weight. Then the smaller the value of (19) is, the better weight we should assign to the criteria.
Let $H$ be the set of incomplete information about criteria weights; to get the optimal weight vector, the following model can be constructed:

$$
\begin{array}{ll}
\text { Min } & E\left(A_{i}\right)=\sum_{i=1}^{n} \sum_{j=1}^{m}\left(1-\sqrt{\frac{1}{2}\left(\left(\mu_{A L}\left(r_{i j}\right)-v_{A L}\left(r_{i j}\right)\right) \times\left(1-\pi_{A L}\left(r_{i j}\right)\right)\right)^{2}+\left(\left(\mu_{A U}\left(r_{i j}\right)-v_{A U}\left(r_{i j}\right)\right) \times\left(1-\pi_{A U}\left(r_{i j}\right)\right)\right)^{2}}\right) \\
\text { s.t. } & w \in H, \quad \sum_{j=1}^{m} w_{i}=1, \quad w_{j} \geq 0, j=1,2, \ldots, m .
\end{array}
$$

By solving model (20) with Excel software, we get the optimal solution $\left(w_{1}, w_{2}, \ldots, w_{m}\right)^{T}$. below.

In summary, the evaluation procedure proposed is listed

Step 1. Collect data for three given attributes.

Step 2. Calculate the weight vector $W=\left(w_{1}, w_{2}, \ldots, w_{m}\right)^{T}$ by solving model (20).
Step 3. Utilize the decision information given in matrix $D$ and the IVIF-WGA operator to derive the collective overall values $z_{i}(i=1,2, \ldots, n)$ of the alternative $A_{i}$.

$$
z_{i}=F_{w}\left(r_{i 1}, r_{i 2}, \ldots, r_{i m}\right), \quad i=1,2, \ldots, n .
$$

Step 4. Calculate the scores $S\left(z_{i}\right)(i=1,2, \ldots, n)$ of the collective overall values to rank all the alternatives $A_{i}(i=$ $1,2, \ldots, n)$. 
4.2. Implementation in Case. In this section, we apply the proposed methodology to evaluate the EO of four online P2P lending platforms and rank them based on their final EO scores.

Step 1. Suppose that a lending expert in a financial management firm is assessing the EO of four online P2P lending platforms, $A=\left\{A_{1}, A_{2}, A_{3}, A_{4}\right\}$. In addition, the lending expert is only comfortable with providing his assessment of each alternative on each attribute as an IVIFS and the evaluation matrix is

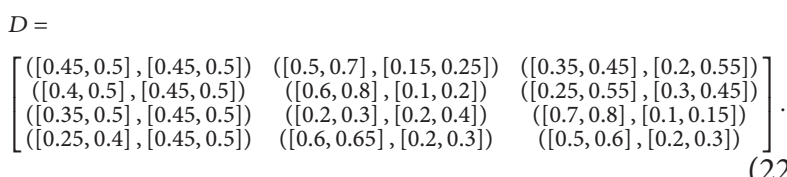

Moreover, the lending expert can only provide his incomplete information on the weights as follows:

$H=\left\{0.3 \leq w_{1} \leq 0.45,0.25 \leq w_{2} \leq 0.35,0.35 \leq w_{3} \leq 0.4\right\}$.

Step 2. Calculate the weight vector $W=\left(w_{1}, w_{2}, w_{3}\right)^{T}$ by solving model (20):

$$
W=(0.3,0.35,0.35)^{T}
$$

Step 3. Utilize the evaluation information given in matrix $D$ and the IVIF-WGA operator to derive the collective overall values $z_{i}(i=1,2,3,4)$ of the alternative $A_{i}(i=1,2,3,4)$ :

$$
\begin{aligned}
& z_{1}=([0.436,0.568],[0.231,0.406]), \\
& z_{2}=([0.437,0.650],[0.231,0.350]), \\
& z_{3}=([0.467,0.592],[0.200,0.303]), \\
& z_{4}=([0.478,0.569],[0.255,0.350]) .
\end{aligned}
$$

Step 4. Calculate the scores $S\left(z_{i}\right)(i=1,2,3,4)$ of the collective overall values $z_{i}(i=1,2,3,4)$ :

$$
\begin{aligned}
& S\left(z_{1}\right)=0.367 \\
& S\left(z_{2}\right)=0.507 \\
& S\left(z_{3}\right)=0.555 \\
& S\left(z_{4}\right)=0.442 .
\end{aligned}
$$

Rank all the alternatives $A_{i}(i=1,2,3,4)$ in accordance with the score $S\left(z_{i}\right)$ of the collective overall interval-valued intuitionistic fuzzy values $z_{i}(i=1,2,3,4): A_{3}>A_{2}>A_{4}>$ $A_{1}$.

\section{Conclusion}

The ability to assess the level of entrepreneurship of online $\mathrm{P} 2 \mathrm{P}$ lending platforms is an important management tool for the platforms themselves and for other organizations. This paper describes an approach to measure the entrepreneurship orientation of online P2P lending platforms. Though many information measures have been developed, still there is scope that better measures can be developed, which will find applications in a variety of fields. In this paper, firstly, some existing measures of entropy are reviewed. Then some examples are applied to show that some existing entropy measures are not always effective in some cases. At the same time, a new entropy measure of interval-valued intuitionistic fuzzy sets is proposed by using cotangent function to overcome limitations of the existing methods. Two examples are made to show that the proposed entropy measure is more reasonable than some existing entropy measures. Therefore, the proposed entropy measure can provide a useful way for measuring the fuzziness of IVIFSs more effectively. Moreover, an evaluation procedure is proposed to measure entrepreneurship orientation of online P2P lending platforms. Finally, a case is used to demonstrate the effectiveness of this method.

\section{Conflict of Interests}

The authors have declared that no conflict of interests exists.

\section{Acknowledgment}

This paper was supported by the National Natural Science Foundation of China (no. 71221061 and no. 71210003).

\section{References}

[1] A. Bachmann, A. Becker, D. Buerckner et al., "Online peer-topeer lending-a literature review," Journal of Internet Banking and Commerce, vol. 16, no. 2, 2011.

[2] M. Herzenstein, R. L. Andrews, U. M. Dholakia, and E. Lyandres, "The democratization of personal consumer loans? Determinants of success in online peer-to-peer lending communities," SSRN Working Paper, 2008.

[3] M. Klafft, "Peer to peer lending: auctioning microcredits over the internet," SSRN Working Paper, 2008.

[4] I. Galloway, "Peer-to-peer lending and community development finance," Community Development Investment Center Working Paper, 2009.

[5] S. Kumar, Bank of One: Empirical Analysis of Peer-To-Peer Financial Marketplace, Association for Information Systems, Keystone, Colo, USA, 2007.

[6] M. Lin, Peer-To-Peer Lending: An Empirical Study, Association for Information Systems, San Francisco, Calif, USA, 2009.

[7] L. Larrimore, L. Jiang, S. Gorski, D. Markowitz, J. Zhao, and K. Canlas, "Making an Offer They Can't Refuse: How Borrower Language in Peer-to-Peer Lending Impacts Funding," TOP 3 Student Paper.

[8] J. Duarte, S. Siegel, and L. Young, "Trust and credit: the role of appearance in peer-to-peer lending," The Review of Financial Studies, no. 25, pp. 2455-2483, 2012.

[9] G. Burtch, A. Ghose, and S. Wattal, "Cultural Differences and Geography as Determinants of Online Pro-Social Lending," 2013, http://ssrn.com/abstract=2271298. 
[10] D. G. Pope and J. R. Sydnor, "What's in a picture?: Evidence of discrimination from Prosper.com," Journal of Human Resources, vol. 46, no. 1, pp. 53-92, 2011.

[11] R. Iyer, A. Ijaz Khwaja, E. F. P. Luttmer, and K. Shue, "Screening peers softly: inferring the quality of small borrowers," NBER Working Paper, 2009.

[12] B. C. Collier and R. Hampshire, "Sending mixed signals: multilevel reputation effects in peer-to-peer lending markets," in Proceedings of the ACM Conference on Computer Supported Cooperative Work (CSCW'10), pp. 197-206, Savannah, Ga, USA, February 2010.

[13] U. Brandes, J. Lerner, B. Nick, and S. Rendle, "Network effects on interest rates in online social lending," Informatik, vol. 10, pp. 4-7, 2011.

[14] D. Shen, C. Krumme, and A. Lippman, "Follow the profit or the herd? Exploring social effects in peer-to-peer lending," in Proceedings of the 2nd IEEE International Conference on Social Computing (SocialCom '10), pp. 137-144, August 2010.

[15] H. Yum, B. Lee, and M. Chae, "From the wisdom of crowds to my own judgment in microfinance through online peerto-peer lending platforms," Electronic Commerce Research and Applications, vol. 11, pp. 469-483, 2012.

[16] L. Dezs and G. Loewenstein, "Lenders'blind trust and borrowers' blind spots: a descriptive investigation of personal loans," Journal of Economic Psychology, vol. 33, pp. 996-1011, 2012.

[17] J. Zhang and P. Liu, "Rational herding in microloan markets," Management Science, vol. 58, no. 5, pp. 892-912, 2012.

[18] G. T. Lumpkin and G. G. Dess, "Linking two dimensions of entrepreneurial orientation to firm performance: the moderating role of environment and industry life cycle," Journal of Business Venturing, vol. 16, no. 5, pp. 429-451, 2001.

[19] S. A. Zahra and J. G. Covin, "Contextual influences on the corporate entrepreneurship-performance relationship: a longitudinal analysis," Journal of Business Venturing, vol. 10, no. 1, pp. 43-58, 1995.

[20] J. Wiklund and D. Shepherd, "Knowledge-based resources, entrepreneurial orientation, and the performance of small and medium-sized businesses," Strategic Management Journal, vol. 24, no. 13, pp. 1307-1314, 2003.

[21] T.-Y. Chen and C.-H. Li, "Determining objective weights with intuitionistic fuzzy entropy measures: a comparative analysis," Information Sciences, vol. 180, no. 21, pp. 4207-4222, 2010.

[22] M. Zeleny, Multiple Criteria Decision Making, McGraw-Hill, New York, NY, USA, 1982.

[23] C. E. Shannon, "A mathematical theory of communication," Bell System Technical Journal, vol. 27, pp. 379-423, 1948.

[24] E. Szmidt and J. Kacprzyk, "Entropy for intuitionistic fuzzy sets," Fuzzy Sets and Systems, vol. 118, no. 3, pp. 467-477, 2001.

[25] L. A. Zadeh, "Fuzzy sets and systems," in Proceedings of the symposium on systems theory, pp. 29-37, Polytechnic Institute of Brooklyn, New York, NY, USA, 1965.

[26] A. de Luca and S. Termini, "A definition of a nonprobabilistic entropy in the setting of fuzzy sets theory," Information and Control, vol. 20, no. 4, pp. 301-312, 1972.

[27] A. Kaufmann, Introduction to the Theory of Fuzzy SubsetsVol. 1: Fundamental Theoretical Elements, Academic Press, New York, NY, USA, 1975.

[28] R. R. Yager, "On the measure of fuzziness and negation part I: membership in the unit interval," International Journal of General Systems, vol. 5, no. 4, pp. 221-229, 1979.
[29] M. Higashi and G. J. Klir, "Measures of uncertainty and information based on possibility distributions," International Journal of General Systems, vol. 9, no. 1, pp. 43-58, 1982.

[30] B. Kosko, "Fuzzy entropy and conditioning," Information Sciences, vol. 40, no. 2, pp. 165-174, 1986.

[31] B. Kosko, "Fuzziness versus probability," International Journal of General Systems, vol. 17, pp. 211-240, 1990.

[32] B. Kosko, Fuzzy Engineering, Prentice Hall, Englewood Cliffs, NJ, USA, 1997.

[33] O. Parkash, P. K. Sharma, and R. Mahajan, "New measures of weighted fuzzy entropy and their applications for the study of maximum weighted fuzzy entropy principle," Information Sciences, vol. 178, no. 11, pp. 2389-2395, 2008.

[34] F. H. Lotfi and R. Fallahnejad, "Imprecise shannon's entropy and multi attribute decision making," Entropy, vol. 12, no. 1, pp. 5362, 2010.

[35] L. A. Zadeh, "The concept of a linguistic variable and its application to approximate reasoning-I," Information Sciences, vol. 8, no. 3, pp. 199-249, 1975.

[36] K. T. Atanassov, "Intuitionistic fuzzy sets," Fuzzy Sets and Systems, vol. 20, no. 1, pp. 87-96, 1986.

[37] K. Atanassov and G. Gargov, "Interval valued intuitionistic fuzzy sets," Fuzzy Sets and Systems, vol. 31, no. 3, pp. 343-349, 1989.

[38] W.-L. Gau and D. J. Buehrer, "Vague sets," IEEE Transactions on Systems, Man and Cybernetics, vol. 23, no. 2, pp. 610-614, 1993.

[39] P. Burillo and H. Bustince, "Entropy on intuitionistic fuzzy sets and on interval-valued fuzzy sets," Fuzzy Sets and Systems, vol. 78, no. 3, pp. 305-316, 1996.

[40] W.-L. Hung and M.-S. Yang, "Fuzzy entropy on intuitionistic fuzzy sets," International Journal of Intelligent Systems, vol. 21, no. 4, pp. 443-451, 2006.

[41] Q.-S. Zhang and S.-Y. Jiang, "A note on information entropy measures for vague sets and its applications," Information Sciences, vol. 178, no. 21, pp. 4184-4191, 2008.

[42] J. Ye, "Two effective measures of intuitionistic fuzzy entropy," Computing, vol. 87, no. 1-2, pp. 55-62, 2010.

[43] C.-P. Wei, P. Wang, and Y.-Z. Zhang, "Entropy, similarity measure of interval-valued intuitionistic fuzzy sets and their applications," Information Sciences, vol. 181, no. 19, pp. 42734286, 2011.

[44] Y. Wang and Y.-J. Lei, "A technique for constructing intuitionistic fuzzy entropy," Kongzhi yu Juece/Control and Decision, vol. 22, no. 12, pp. 1390-1394, 2007.

[45] G. S. Huang and Y. S. Liu, "The fuzzy entropy of vague sets based on non-fuzzy sets," Computer Applications and Software, vol. 22, pp. 16-17, 2005.

[46] Q.-S. Zhang, S. Jiang, B. Jia, and S. Luo, "Some information measures for interval-valued intuitionistic fuzzy sets," Information Sciences, vol. 180, no. 24, pp. 5130-5145, 2010.

[47] H. Bustince and P. Burillo, "Vague sets are intuitionistic fuzzy sets," Fuzzy Sets and Systems, vol. 79, no. 3, pp. 403-405, 1996.

[48] C. Cornelis, K. T. Atanassov, and E. E. Kerre, "Intuitionistic fuzzy sets and interval-valued fuzzy sets: a critical comparison," in Proceedings of 3rd European Conference on Fuzzy Logic and Technology (EUSFLAT '03), pp. 159-163, Zittau, Germany, 2003.

[49] G. Deschrijver and E. E. Kerre, "On the relationship between some extensions of fuzzy set theory," Fuzzy Sets and Systems, vol. 133, no. 2, pp. 227-235, 2003. 
[50] I. K. Vlachos and G. D. Sergiadis, "Subsethood, entropy, and cardinality for interval-valued fuzzy sets-an algebraic derivation," Fuzzy Sets and Systems, vol. 158, no. 12, pp. 1384-1396, 2007.

[51] J. Ye, "Multicriteria fuzzy decision-making method using entropy weights-based correlation coefficients of intervalvalued intuitionistic fuzzy sets," Applied Mathematical Modelling, vol. 34, no. 12, pp. 3864-3870, 2010.

[52] Z.-S. Xu, "Methods for aggregating interval-valued intuitionistic fuzzy information and their application to decision making," Control and Decision, vol. 22, no. 2, pp. 215-219, 2007.

[53] Z.-S. Xu and J. Chen, "An approach to group decision making based on interval-valued intuitionistic judgment matrices," System Engineering Theory and Practice, vol. 27, no. 4, pp. 126133, 2007.

[54] D. Miller, "The correlates of entrepreneurship in three types of firms," Management Science, vol. 29, no. 7, pp. 770-791, 1983.

[55] J. G. Covin and D. P. Slevin, "Strategic management of small firms in hostile and benign environments," Strategic Management Journal, vol. 10, no. 1, pp. 75-87, 1989. 


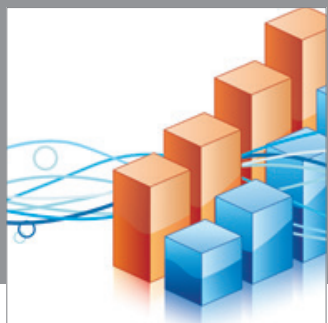

Advances in

Operations Research

mansans

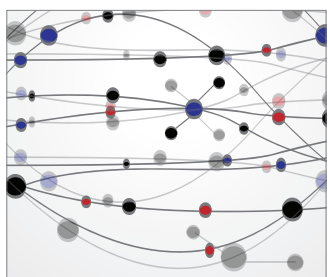

The Scientific World Journal
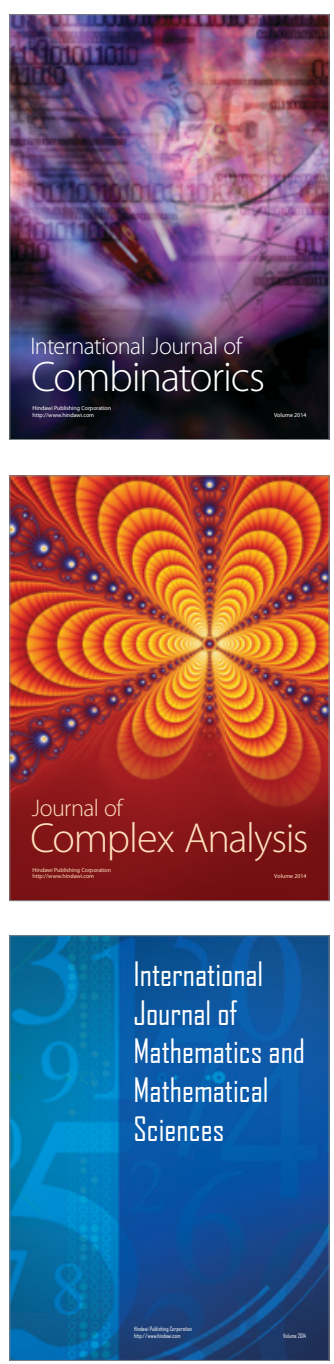
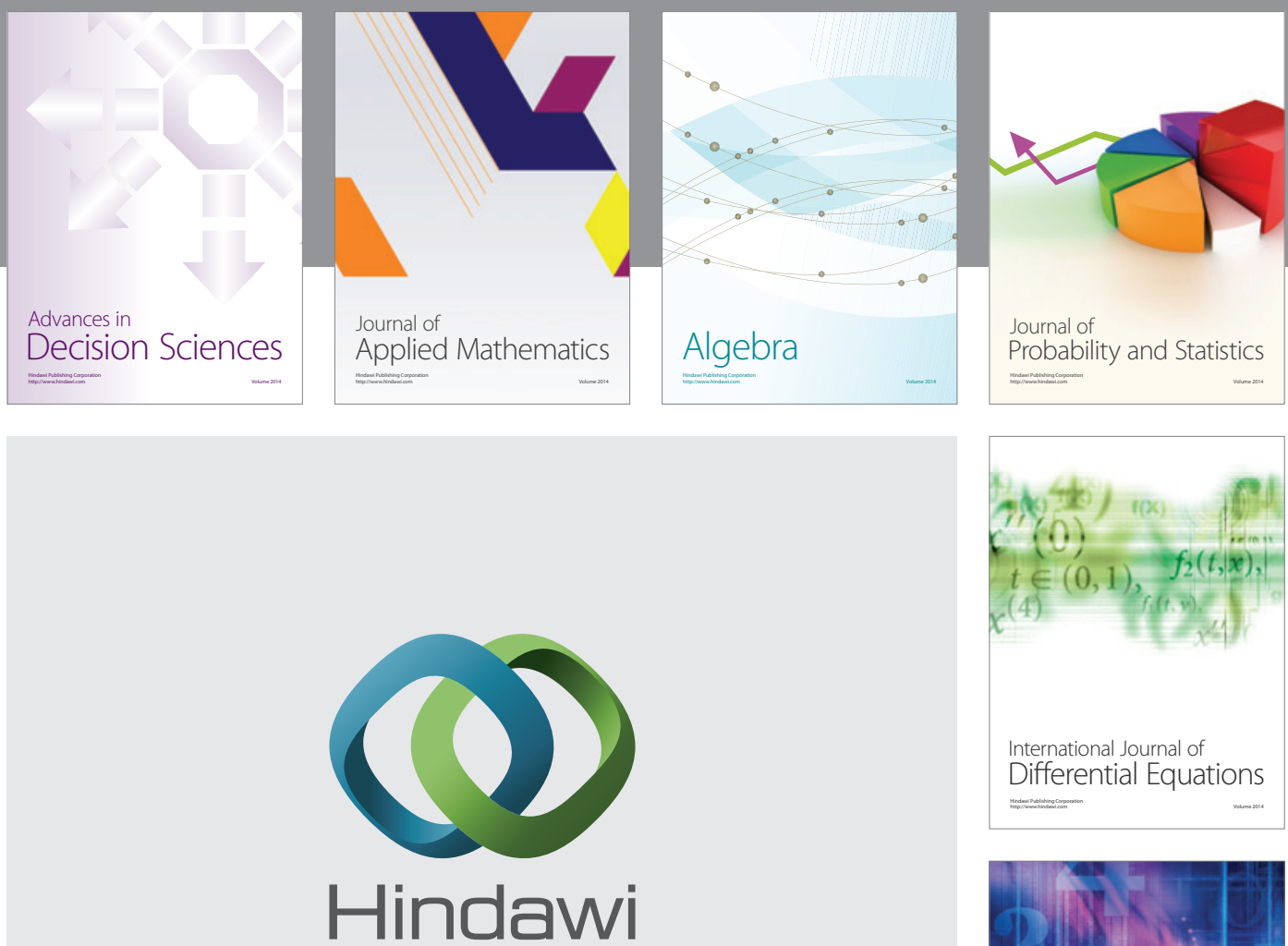

Submit your manuscripts at http://www.hindawi.com
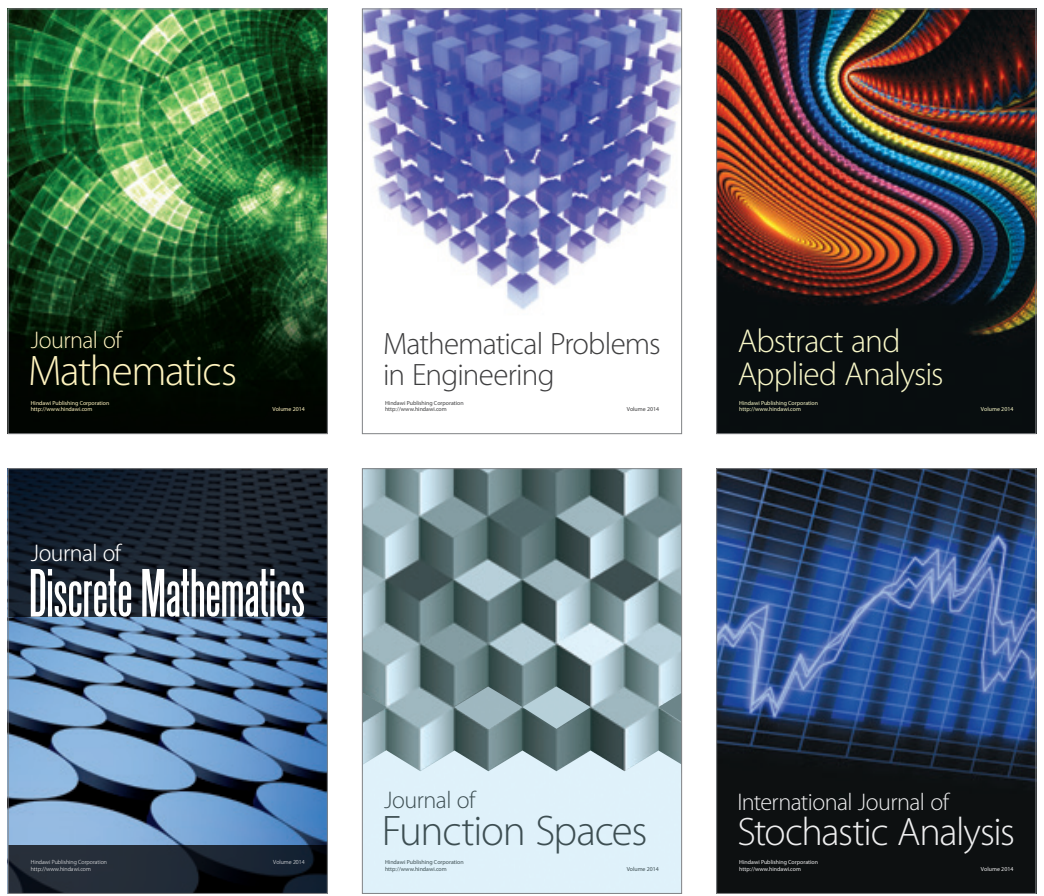

Journal of

Function Spaces

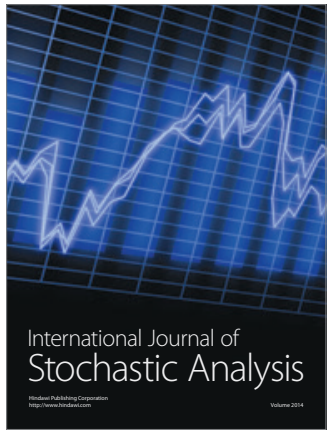

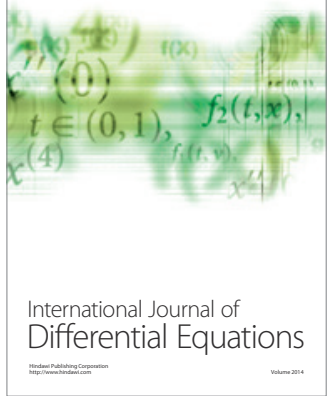
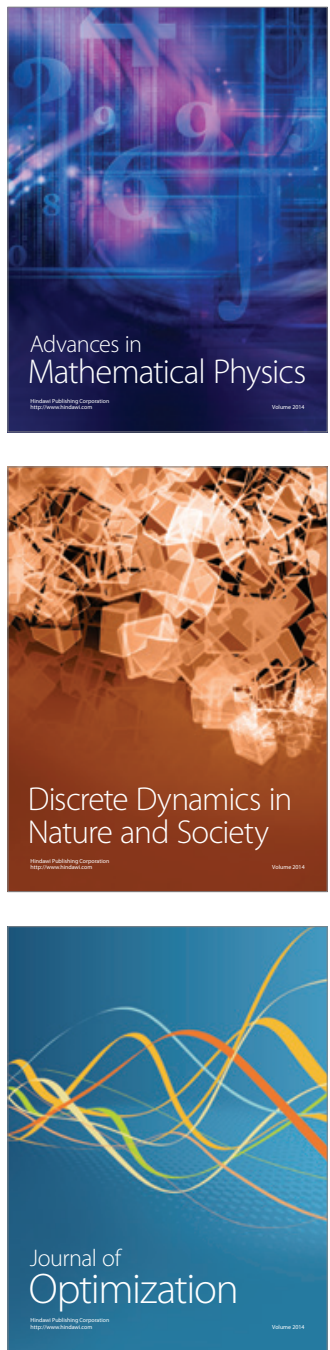